\title{
Conf $-950201--9$
}

LA-UR- 95-654

Title:

HYDROSTATIC EXTRUSION OF HTSC/AG COMPOSITE CONDUCTORS

Author(s):

John F. Bingert, MST-6

Barry L. Bingham, MST-6

Robert J. Sebring, MST-6

Ann M. Kelly, MST-6

Submitted to:

Presentation:
124th TMS Annual Meeting
Las Vegas, NV
February 12-16, 1995
Proceedings:
Journal of Electronic Materials

RFCFIVED

MAR 101995

Los Alamós

NATIONAL LABORATORY

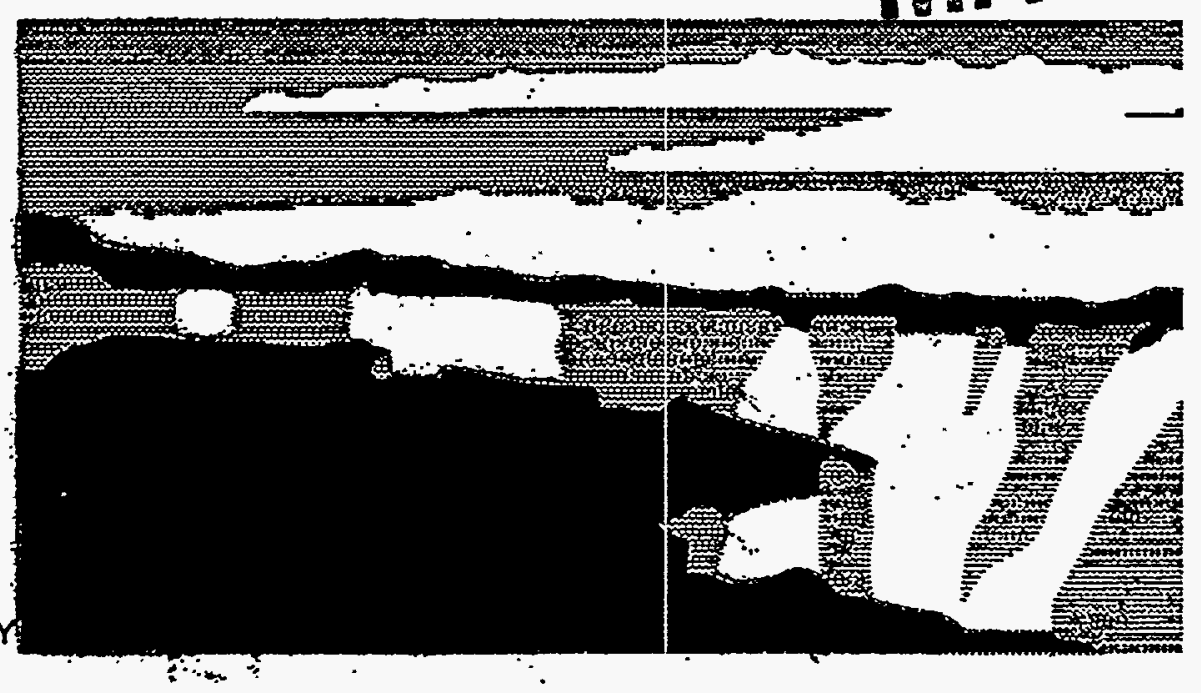

Los Alamos National Laboratory, an affirmative action/equal opportunity employer, is operated by the University of Calfornia for the U.S. Department of Energy

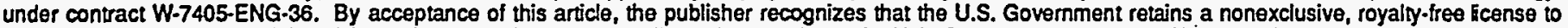
publish or reproduce the published form of this contribution, or to allow others to do so, for U.S. Government purposes. The Los Alamos National Laboratory requests that the publisher identify this article as work performed under the auspices of the U.S. Department of Energy. 


\title{
Hydrostatic Extrusion of BSCCO/Ag Composite Wire
}

\author{
J.F. Bingert, B.L. Bingham, R.J. Sebring, and A.M.Kelly \\ Los Alamos National Laboratory, MS G770 \\ Los Alamos, NM 87545
}

\begin{abstract}
The application of hydrostatic extrusion processing to composite wire fabrication offers several advantages over conventional reduction techniques. These include enhanced uniformity, increased reduction capability, and successful extrusion of normally brittle materials. Specifically, this work involved an experiment to screen the effects of seven extrusion process parameters on the uniformity and density of as-extruded BSCCO-core wire, and the required extrusion pressure. Results suggest the following factors to be potentially significant: 1) back pressure, extrusion ratio, and die angle on core uniformity, 2) packing method, extrusion ratio, silver powder additions, and temperature on density, and 3) extrusion ratio and temperature on extrusion pressure.
\end{abstract}

\section{DISCLAIMER}

\begin{abstract}
This report was prepared as an account of work sponsored by an agency of the United States Government. Neither the United States Government nor any agency thereof, nor any of their employees, makes any warranty, express or implied, or assumes any legal liability or responsibility for the accuracy, completeness, or usefulness of any information, apparatus, product, or process disclosed, or represents that its use would not infringe privately owned rights. Reference herein to any specific commercial product, process, or service by trade name, trademark, manufacturer, or otherwise does not necessarily constitute or imply its endorsement, recommendation, or favoring by the United States Government or any agency thereof. The views and opinions of authors expressed herein do not necessarily state or reflect those of the United States Government or any agency thereof.
\end{abstract}

Key Words: hydrostatic extrusion, HTSC, wire fabrication 


\section{DISCLAIMER}

Portions of this document may be illegible in electronic image products. Images are produced from the best available original document. 


\section{Introduction}

The application of hydrostatic extrusion processing to the fabrication of high-temperature superconductor (HTSC) wire is potentially attractive for several reasons. Although less efficient than conventional extrusion, it is particularly suited for high value-added composite materials. By virtue of a fluid pressure medium, a nearly ideal lubrication condition exists during deformation, thus providing larger, more uniform reductions at lower temperatures for given applied pressures. The desired characteristics of asdeformed superconductor wire include dimensional uniformity of the cross-section, high relative density to enhance the sinter/reaction step, and a large core:clad area ratio to maximize engineering critical current density $\left(\mathrm{J}_{\mathrm{e}}\right)$. Depending on the family of HTSC powders utilized, wire which fulfills the above criteria may be thermally processed from the as-extruded condition, or rolled into tape geometries to afford desired crystallographic texture per the conventional oxide-powder-in-tube process ${ }^{1}$. The development of the former process would produce economic advantages and expand potential applications.

The purpose of this investigation was to estimate the effects of seven processing factors on the extrusion of round, silver-clad/BSCCO-core composite wires to determine those having the largest effect on selected responses, and thus deserving of further investigation toward process optimization.

\section{Experimental}

Table 1 outlines the seven factors selected for study and their definitions within the context of this experiment. Two levels were chosen for each factor, designated by "+" and "_" column headings, and these represent the range of experimental conditions. Each factor was selected by virtue of either its potential influence on the extrusion process or from past experience with drawn and rolled oxide powder-in-tube processed wires ${ }^{2}$. Factors are divided between billet properties (AR, SA, and PM) and extrusion processing conditions (XR, DA, BP, and XT).

The experiment was designed to perform a primary screen of relevant factors as efficiently as possible, and as such is comprised of a very sparse matrix. The experimental matrix is presented in Table 2, using factor designations introduced in Table 1. The design is formally a $2^{7-4}$, resolution III saturated fractional factorial ${ }^{3}$. Comprised of eight experimental runs, it essentially represents $1 / 16$ th of the full factorial. Main effects can be estimated from this design, but main effects are confounded with interactions, thereby rendering interactions inestimable.

To satisfy the experimental design, eight extrusion billets were prepared by fabricating blind-holed tubes and plugs of various dimensions from 99.95 pure silver. The HTSC material employed was $\mathrm{Bi}-2223$ precursor powder, consisting of a stoichiometric mix of $\mathrm{Bi}-2212, \mathrm{CuO}_{2}$, and $\mathrm{Ca}_{2} \mathrm{CuO}_{3}$. The mean particle size was $4.4 \pm 2 \mu \mathrm{m}$. After machining, the tubes were etched with $50 \% \mathrm{HNO}_{3}$ to provide a roughened surface for enhanced lubricant entrainment during extrusion. Additional lubrication was provided by rubbing 
the billet surfaces with $\mathrm{MoS}_{2}$. Silver additions (SA(t)) consisted of a fine flake morphology powder, selected to improve core deformation characteristics. For the $\mathrm{PM}(+)$ condition HTSC rods were prepared by cold isostatically pressing at $345 \mathrm{MPa}$ and machining the resultant compacts to match the bore of the billets. Following core loading, tubes were sealed by TIG welding.

The equipment utilized for extrusions was an Innovare LES hydrostatic extrusion press with a $1.27 \mathrm{~cm}$-diameter billet chamber rated for $1.7 \mathrm{GPa}$ at room temperature. All extrusions were performed using $3.18 \mathrm{~mm}$ dies with either $10^{\circ}$ or $20^{\circ}$ semi-angle entrance zones. Extrusion ratios were varied by starting with appropriately different billet outer diameters. Along with the two die angles employed, this resulted in four different externally profiled billets. Back pressure was provided by extruding into a larger diameter receiver chamber. Elevated temperatures were realized in the billet chamber by external contact with a resistance heater. Peanut oil was employed as the pressure medium at room temperature, while methyl alkyl silicone was used for elevated temperature extrusions. Real time data were acquired for ram displacement, chamber pressures, and temperature. Metallographic specimens of the as-extruded wire were prepared for microstructural examination, and the longitudinal midplane sections digitized for dimensional analysis.

\section{Results and Discussion}

Each of the billets representing runs 1 through 8 was extruded to $3.18 \mathrm{~mm}$ diameter wire. The results from extrusion processing are most succinctly shown as pressuredisplacement curves. A curve for a typical extrusion into atmosphere (Run 6) is shown in Figure 1. The curve is composed of three regions: I) a linear increase in pressure corresponding to compression of the extrusion fluid, II) a breakover and subsequent leveling of pressure indicating extrusion of the silver nose, and III) a transition and leveling related to the entrance of the BSCCO core through the die and subsequent extrusion of the composite structure. The lack of a breakthrough pressure peak into region II, along with constant pressures observed during the steady-state portions of the extrusion indicate excellent lubrication conditions prevailed. The upward transition in pressure as the BSCCO core is extruded signifies the greater flow stress of the powder compared to silver. A rule of mixtures calculation may be employed to estimate the extrusion pressure for composite billets ${ }^{4}$ :

$$
P_{\text {Composite }}=P_{\text {HTSCAHTC }}+P_{A g} A_{A g}
$$

where $\mathrm{P}=$ the extrusion pressure and $\mathrm{A}=$ the fractional cross-section area. Given $\mathrm{P}_{\mathrm{Ag}}=$ $435 \mathrm{MPa}$, this equation yields $615 \mathrm{MPa}$ for $\mathrm{P}_{\mathrm{HTSC}}$. In other words, an equivalent extrusion with a billet comprised of only BSCCO powder (in the condition outlined for run 6, i.e. isostatically pressed, no silver additions) would be expected to extrude at 615 $\mathrm{MPa}$. This run probably represents the powder at its highest flow stress. Furthermore, 
the extrusion pressure is commonly related to the extrusion ratio through the following equation 5 :

$$
P=K \ln R
$$

where $R$ is the extrusion ratio $\left(A_{o} / A_{f}\right)$, and $K=$ the extrusion constant, a parameter which accounts for flow stress, friction, and redundant work during deformation through the die. Although variable with processing conditions, $\mathrm{K}$ is useful as a rough guide to predict extrusion pressures with different ratios or composite area fractions, since quantitative information on friction and redundant work are difficult to acquire. Solving for $\mathrm{K}$ for the hypothetical monolithic BSCCO billet yields $\approx 445 \mathrm{MPa}$. Equivalent calculations were performed for run 3, which may be expected to represent the low end of the flow stress spectrum. The hand-packed BSCCO core with silver additions renders $P_{\mathrm{HTSC}}=365 \mathrm{MPa}$ and $\mathrm{K} \approx 260 \mathrm{MPa}$. For statistical analysis purposes below, extrusion pressure is taken as the runout pressure in the composite section of the billet (region III). The extrusion pressure for runs with back pressure is defined as the billet chamber pressure less the receiver pressure at runout.

As-extruded product was analyzed for dimensional uniformity and geometric density. These results, along with extrusion pressures, are presented in Table 3. Digitized images from longitudinal sections were used to compute the mean, standard deviation, and coefficient of variation of core thickness along the lengths of the wires. Coefficient of variation was adopted as the metric for uniformity, and computed as the standard deviation of the thickness measurements divided by the mean thickness, expressed as a percentage. As-extruded densities were determined geometrically from the mean thickness, extrusion ratio, and initial (as-packed) densities. Percent theoretical densities were calculated using the values of $6.5 \mathrm{~g} / \mathrm{cm} 3$ for $\mathrm{SA}(-)$ runs, and 7.03 for runs with silver-addition powder.

Core uniformities ranged from coefficient of variations of $1 \%$ (run 6 ) to $50 \%$ (run 8 ). Figure 2 shows light micrographs of representative longitudinal sections from runs 6 (a) and 8 (b), along with samples from their respective digitized core thickness traces. Faint diagonal cracks can be observed in the core from run 6 , indicating shear-induced defects are present in even the most uniform extrusion. Shear cracks form in brittle materials under compressive loads. Cracking is more severe in run 8 , and is accompanied by faulting and realignment of the BSCCO into blocks. The root cause for nonuniform deformation in composite structures is the mechanical mismatch between cladding and core $^{6}$. As the BSCCO core densifies as it is compressed in the inlet zone of the die, its flow stress increases, thereby increasing the mismatch. In uniaxial tensile strain, this condition would manifest itself through a single necking instability. However, due to the compressive constraints encountered in the extrusion process, a periodic instability develops. The correlation between increased core flow stress and instability development was observed from microhardness measurements taken along a longitudinal section from the die inlet zone for sample 1. A steep increase in hardness from VHN 150 to 175 over a $0.5 \mathrm{~mm}$ length coincided with the onset of a necking instability. Cracks aligned normal to the length of the wire were observed in other samples. These cracks are associated 
with tensile stresses oriented along the wire axis, and result from the silver clad's lower flow stress. The clad responds to applied stresses with larger plastic strains than the core, thereby transmitting longitudinal tensile stresses.

Core thickness coefficients of variation, percent theoretical densities, and extrusion pressures were employed as responses to measure main effects for each of the seven factors. Table 4 presents these main effects with the results of an analysis of variance (ANOVA) calculation. Main effects were calculated by subtracting the sum of responses at the "-" level from the sum of responses at the " + " level. A positive main effect signifies that the " + " level leads to larger responses, while a negative main effect infers the opposite. The ANOVA results are given as significance levels in percentage form. The significance levels are taken to be $(1-\alpha) * 100$, where $\alpha$ is the probability of the null hypothesis as applied to the $F$ ratio test. This test measures the probability that the mean responses come from separate sample populations, and gives an indication of the significance of variations due to each factor.

Regarding the coefficient of variation response, a minimum value is preferred. The fact that all main effects are positive values indicates (without regard to significance) that the "." levels of all factors tend to enhance core uniformity. The ANOVA shows back pressure to be most significant, followed by extrusion ratio and die angle. Back pressure has been shown ${ }^{4}$ to reduce defect formation in composite extrusions, so therefore its strong tendency to promote nonuniform cores is puzzling. Its effect on increasing billet chamber pressures (needed to overcome the receiver pressure) may have increased core hardness and exacerbated core:clad material property mismatch. Lubrication conditions may also have deteriorated at the higher pressures. Larger extrusion ratios and die angles may be expected to result in less uniformity due to increased redundant deformation. Surprisingly, the effects of packing method and area ratio were not significant.

Maximum values of relative density are seeked. Isostatically pressed cores, large extrusion ratios, and silver additions are desired in this respect, while elevated temperatures may lower densities. These results suggest starting with higher densities results in the same, and increasing compressive stresses on the core through larger reductions or cold working increases as-extruded densities. The use of a stronger clad material should have the same positive impact on density. Silver additions are probably beneficial in this regard by filling microporosity at high pressures.

Extrusion pressures are best minimized for a given extrusion ratio, as this increases the maximum obtainable ratio and results in a more commercially attractive process. Only extrusion ratio itself and temperature are significant factors affecting the extrusion pressure. Increasing the temperature beyond $180^{\circ} \mathrm{C}$ should have a much greater effect than that observed. However, since the flow stress of silver is much more temperature sensitive than BSCCO at moderate temperatures, the mechanical mismatch will also increase. A surprising observation is the apparent insensitivity of any response to the 
area fraction of BSCCO. This is encouraging for purposes of increasing current densities based on total conductor cross-section.

\section{Conclusions}

The results of the hydrostatic extrusion screening experiment on BSCCO/Ag conductors suggest the following:

1) Uniform core structures are encouraged by extruding into atmosphere, using modest extrusion ratios, and decreasing die angles.

2) Maximizing core density is achieved through isostatically pressed cores, large extrusion ratios, silver additions, and extruding at room temperature (i.e. increasing clad flow stress).

3) Reductions in extrusion pressure are affected by lowering extrusion ratios and increasing extrusion temperature. 
Table 1: Factors and their associated levels employed for the designed experiment.

\begin{tabular}{|c|c|c|c|}
\hline & \multicolumn{2}{|c|}{ Levels } & - \\
\hline Factor & Description & + & $15 \%$ \\
AR & $\begin{array}{c}\text { Cross-section Area } \\
\text { ratio (BSCCO } \\
\text { core):(Total) }\end{array}$ & $25 \%$ & 0 \\
\hline $\begin{array}{c}\text { Silver Addition } \\
\text { SA }\end{array}$ & $\begin{array}{c}\text { Silver flake powder } \\
\text { blended with } \\
\text { BSCCO }\end{array}$ & $20^{\mathrm{w} / 0}$ & Manually packed \\
\hline $\begin{array}{c}\text { Packing Method } \\
\text { PM }\end{array}$ & $\begin{array}{c}\text { Method of loading } \\
\text { BSCCO core into } \\
\text { billet }\end{array}$ & $\begin{array}{c}\text { Cold Isostatically } \\
\text { Pressed (345 MPa) } \\
\text { rod }\end{array}$ & 4 \\
\hline $\begin{array}{c}\text { Extrusion Ratio } \\
\text { XR }\end{array}$ & $\begin{array}{c}\text { Area ratio } \\
\text { initial:final }\end{array}$ & 8 & $10^{\circ}$ \\
\hline $\begin{array}{c}\text { Die angle } \\
\text { DA }\end{array}$ & $\begin{array}{c}\text { Semi-angle of } \\
\text { extrusion die }\end{array}$ & $20^{\circ}$ & 0 \\
\hline $\begin{array}{c}\text { Back Pressure } \\
\text { BP }\end{array}$ & $\begin{array}{c}\text { Pressure maintained } \\
\text { in receiving } \\
\text { chamber }\end{array}$ & $0.3 \times$ pressure in \\
billet chamber & Room Temperature \\
\hline $\begin{array}{c}\text { Extrusion } \\
\text { Temperature } \\
\text { XT }\end{array}$ & $\begin{array}{c}\text { Temperature } \\
\text { maintained in billet } \\
\text { chamber }\end{array}$ & $180^{\circ} \mathrm{C}$ & \\
\hline
\end{tabular}

Table 2: $2^{7-4}$ fractional factorial design for BSCCO/Ag hyddrostatic extrusions.

\begin{tabular}{|c|c|c|c|c|c|c|c|}
\hline Run & AR & SA & PM & XR & DA & BP & XT \\
\hline 1 & - & - & - & + & + & + & - \\
\hline 2 & + & - & - & - & - & + & + \\
\hline 3 & - & + & - & - & + & - & + \\
\hline 4 & + & + & - & + & - & - & - \\
\hline 5 & - & - & + & + & - & - & + \\
\hline 6 & + & - & + & - & + & - & - \\
\hline 7 & - & + & + & - & - & + & - \\
\hline 8 & + & + & + & + & + & + & + \\
\hline
\end{tabular}


Table 3: Measured responses for hydrostatic extrusion runs.

\begin{tabular}{|c|c|c|c|}
\hline Run & $\begin{array}{c}\text { Core Thickness } \\
\text { Coefficient of } \\
\text { Variation (\%) }\end{array}$ & $\begin{array}{c}\text { \% Theoretical } \\
\text { Density of as- } \\
\text { extruded core }\end{array}$ & $\begin{array}{c}\text { Extrusion Pressure } \\
\text { (MPa) }\end{array}$ \\
\hline 1 & 40.7 & 84.3 & 880 \\
\hline 2 & 9.2 & 54.0 & 335 \\
\hline 3 & 3.0 & 70.8 & 320 \\
\hline 4 & 8.4 & 77.5 & 805 \\
\hline 5 & 9.4 & 78.2 & 600 \\
\hline 6 & 1.0 & 75.4 & 480 \\
\hline 7 & 13.6 & 90.3 & 495 \\
\hline 8 & 49.8 & 90.7 & 565 \\
\hline
\end{tabular}

Table 4: Results from statistical analysis of hydrostatic extrusion responses.

\begin{tabular}{|c|c|c|c|c|c|c|}
\hline \multirow[b]{2}{*}{ Factor } & \multicolumn{2}{|c|}{$\begin{array}{c}\text { Core Thickness } \\
\text { Coefficient of Variation }\end{array}$} & \multicolumn{2}{|c|}{ Percent Theoretical Density } & \multicolumn{2}{|c|}{ Extrusion Pressure } \\
\hline & $\begin{array}{l}\text { Main Effect } \\
(\%)\end{array}$ & $\begin{array}{l}\text { \% Level of } \\
\text { Significance }\end{array}$ & $\begin{array}{l}\text { Main Effect } \\
(\%)\end{array}$ & $\begin{array}{l}\text { \% Level of } \\
\text { Significance }\end{array}$ & $\begin{array}{l}\text { Main Effect } \\
(\mathrm{MPa})\end{array}$ & $\begin{array}{l}\text { \% Level of } \\
\text { Significance }\end{array}$ \\
\hline $\mathrm{AR}$ & 0.4 & Not Signif. & -6.5 & NS & -27.5 & NS \\
\hline$\overline{\mathrm{SA}}$ & 3.6 & NS & 9.4 & 70 & -27.4 & NS \\
\hline$\overline{\mathrm{PM}}$ & 3.1 & $\overline{N S}$ & 12.0 & 82 & -50.0 & $\overline{N S}$ \\
\hline $\mathrm{XR}$ & 20.4 & 88 & 10.1 & 73 & 305 & 98 \\
\hline$\overline{\mathrm{DA}}$ & 13.5 & 65 & 5.3 & NS & 2.5 & $\overline{\text { NS }}$ \\
\hline BP & 22.8 & 93 & 4.4 & NS & 17.5 & NS \\
\hline $\mathrm{XT}$ & 1.9 & NS & -8.4 & $\overline{64}$ & -210 & 85 \\
\hline
\end{tabular}


Figure 1

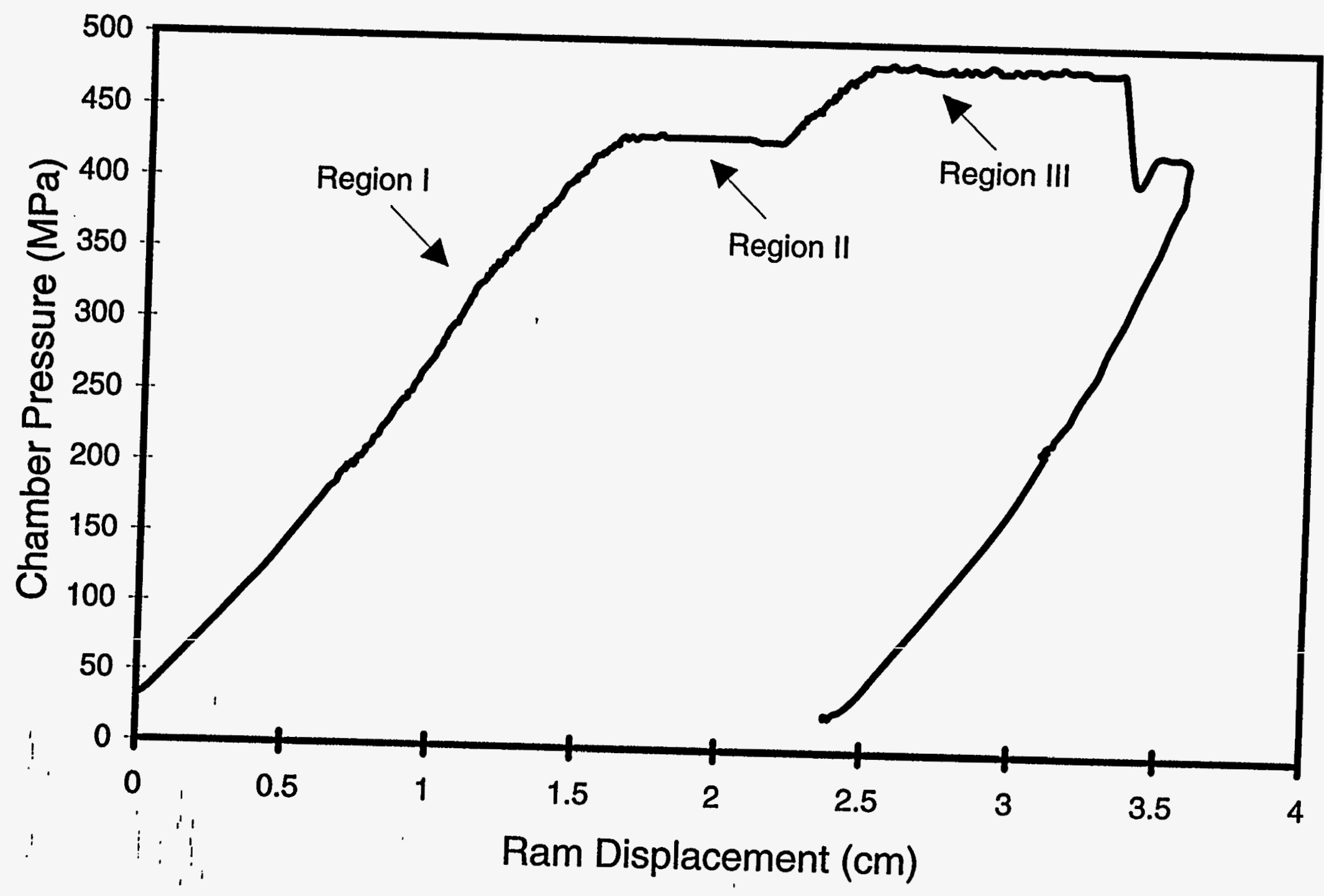

Page 1 

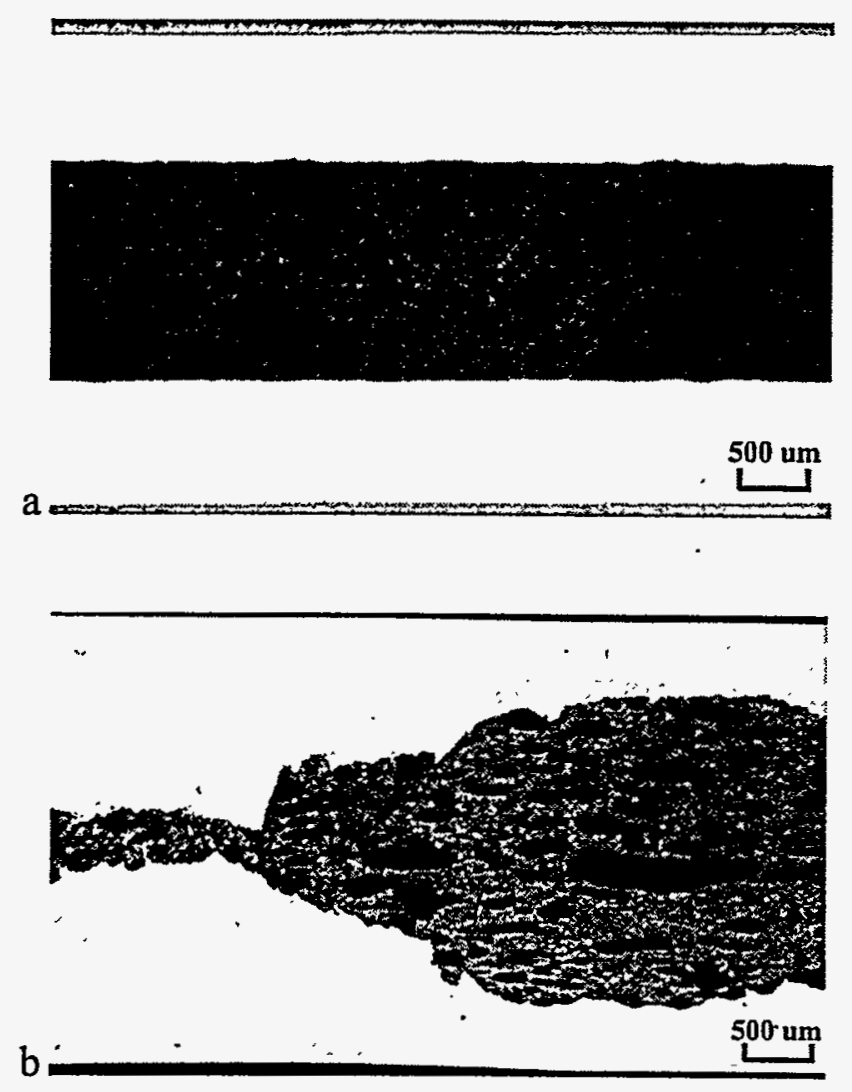
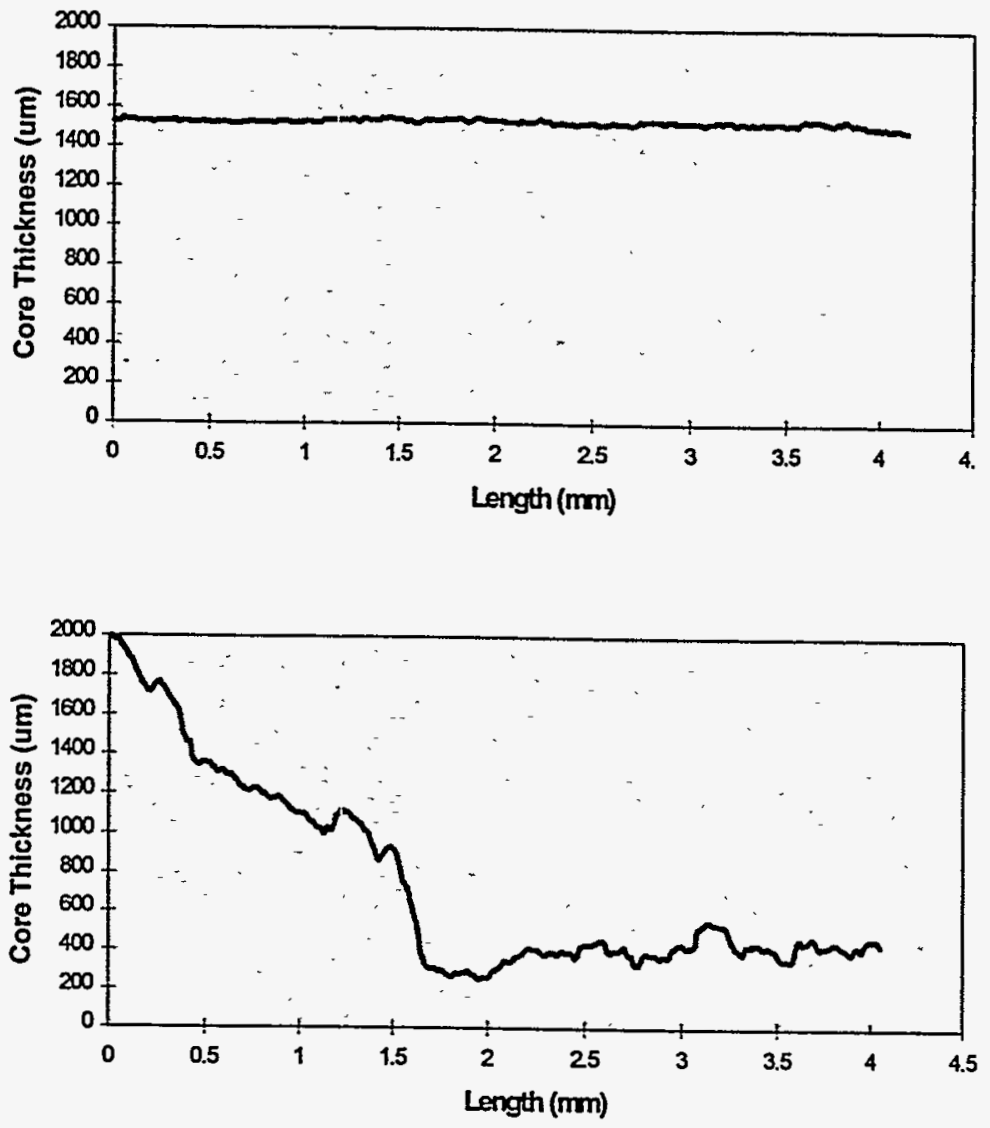

Figure 2. 
References

1. K.H. Sandhage, G.N. Riley and W.L. Carter, J. Metals 43, 21 (1991).

2. G.E. Box, W.G. Hunter, and J.S. Hunter, Statistics for Experimenters, WileyInterscience, New York.

3. D.A. Korzekwa, J.F. Bingert, E.J. Podtburg, and P. Miles, Applied Superconductivity, 2, 261 (1994).

4. N. Inoue and M. Nishihara, Hydrostatic Extrusion: Theory and Applications, Elsevier Applied Science, Essex, England.

5. W.A. Backofen, Deformation Processing, Addison Wesley, Reading, MA.

6. P.S. Steif, J. Applied Metalworking, 4, 317 (1987).

Figure 1: Pressure-displacement curve for hydrostatic extrusion run 1. Regions referred to in text.

Figure 2: Longitudinal section and digitized core thickness trace for hydrostatic extrusions: a) run $6, b$ ) run 8 . 